\title{
A presença estrangeira em Ventos do apocalipse, de Paulina Chiziane
}

\author{
Márcia Souto Ferreira ${ }^{1}$
}

RESUMO: Este trabalho pretende mostrar como, na obra Ventos do apocalipse, de Paulina Chiziane, apresenta-se a questão do estrangeiro. Usa-se, aqui, o conceito de estrangeiro como o diferente, o excluído, o outro que ameaça e que ocupa o lugar da diferença.

ABSTRACT: This paper intends to show how in the work Ventos do apocalipse, by Paulina Chiziane, presents the question of the foreigner. It is used here, the concept of foreigner with another focus, meaning the alien and the different, the excluded, the other threat and that takes the place of difference.

PALAVRAS-CHAVE: Estrangeiro; Margem; Identidade.

KEYWORDS: Foreigner; Edge; Identity.

Questões ligadas à figura do estrangeiro já foram abordadas por estudiosos de diversas áreas do conhecimento, da política à antropologia, da psicanálise à filosofia. Várias obras literárias apresentam como tema o estrangeiro, ora discutindo a sua incomunicabilidade, ora ressaltando o exotismo ou mesmo a fascinação

1 Mestranda do Programa de Pós-Graduação em literaturas de lingua portuguesa da PUC-Minas - Projeto de Pesquisa: Estratégias narrativas e identidades deslizantes em Venenos de Deus, remédios do Diabo, de Mia Couto. O presente trabalho foi realizado com o apoio do Conselho Nacional de Desenvolvimento Científico e Tecnológico - CNPq - Brasil.Contato: marciasofer@ig.com.br 
que se tem por ele. Essa multiplicidade de abordagens comprova a complexidade do tema e a pertinência de sua discussão.

Pretende-se, neste trabalho, analisar o modo como alguns personagens do livro Ventos do apocalipse, de Paulina Chiziane, relacionam-se com os estrangeiros ou se apresentam na condição de um deles. A obra estudada situa-se no contexto pós-colonial moçambicano, período em que são relevantes as discussões relativas à construção de identidades e, por conseguinte, repensado o lugar que deve ser cedido a representações estrangeiras.

De acordo com conceitos psicanalíticos propostos por Freud, em "Inibição, sintoma e angústia" (1926), o primeiro indivíduo a ser considerado o próximo com quem uma criança tem contato é a mãe (ou a pessoa que cuida da criança). Toda vez que o bebê encontra diante de si alguém que não seja a mãe, haverá um certo desamparo provocado pela ausência do elemento familiar e pela presença estrangeira. Aos poucos, o familiar se estende a outras pessoas com quem a criança trava convivência. Estas, no processo identitário, revelam a necessidade que temos de nos enxergarmos no outro. No entanto, ainda de acordo com Freud (1929), "É sempre possivel unir um considerável número de pessoas no amor, enquanto sobrarem outras para receberem as manifestações de sua agressividade" (FREUD, 1929, p. 136).

Uma das associações que Homi K. Bhabha (2001) faz ao conceito de disseminação, aproxima-o ao contato com a alteridade, que é o que configura a identidade. Bhabha, entretanto, propõe que as pessoas articulem-se em um duplo discurso: o da tradição e o da intermediação, em que são configuradas as relações da diferença. Nessa perspectiva sócio-cultural, as identidades se constroem nos processos de identificações, mas também nas diferenças.

No livro Estrangeiros para nós mesmos, Júlia Kristeva, ao pensar o significante estrangeiro na acepção legal ou política, afirma que "a indiferença é a carapaça do estrangeiro: insensivel, distante, no fundo ele parece fora de alcance das agressões que, contudo, sente com a 
vulnerabilidade de uma medusa." (1994, p. 15). Ainda de acordo com essa autora, o estrangeiro só sai desse estado de indiferença quando "se liga seja a uma causa, a uma profissão, ou a uma pessoa” (p. 17).

As considerações até aqui observadas permitem estabelecer algumas considerações sobre o elemento estrangeiro na narrativa de Ventos do apocalipse, e sobre as manifestações de agressividades referentes a ele e também como se dá a reação.

\section{Os de Macuácua}

No texto de Paulina Chiziane, narra-se a saga do povo de Mananga e sua busca por sobrevivência. Na primeira parte da narrativa, refugiados da aldeia vizinha, Macuácua, adentram Mananga, fugindo dos efeitos da guerra civil que assola o país. Os de Macuácua são alvo de hostilidade por não pertencerem ao grupo/comunidade que, narcisicamente, não se reconhece nos refugiados:

A chegada dessas pessoas de Macuácua é uma agressão, uma invasão e causa revolta em todos de Mananga. A recepção é hostil e as atitudes fratricidas. O nosso povo sente o desejo louco de defender o território à força, mas as autoridades impõem-se, malditas autoridades. (CHIZIANE, 1993, p.80)

A guerra promove a exclusão e mina as noções de solidariedade. Num contexto de carências, os invasores representam uma ameaça ainda maior: "Deixaram esses forasteiros fixarem-se no nosso solo, nesta terra tão pobre e seca. Vieram apenas para roubar-nos os alimentos, a paz e o sossego com os seus problemas." (CHIZIANE, p. 80)

Mananga vivia um momento de grandes dificuldades provocadas pela seca, mas também pela transição do poder político. Sianga, o antigo régulo da aldeia, não aceitava a perda do poder. O país vive uma guerra fratricida e um tempo de rápidas e relevantes mudanças. Os valores tradicionais, que conferiam identidade aos membros da comunidade, desconfiguram-se. À procura de sua identidade, os de Mananga disfarçam o vazio do seu projeto identitário 
agredindo o diferente. "Diante do estrangeiro, sinto-me novamente membro de uma comunidade daqueles que, assim como eu, o excluem, negam-lhe seus direitos, o odeiam.” (ARBEX JR., 1998, p. 18)

O poder vigente, composto por membros da FRELIMO, considerava essencial, no projeto de nação que desejam construir, que fossem eliminados regionalismos, pois os considerava nocivos à unidade nacional pretendida. Na narrativa de Chiziane também há espaço para reflexões acerca desse poder estrangeiro que ocupava as aldeias.

Mesmo sendo proibidos pelos governantes de segregarem os de Macuácua, havia como criar estratégias para hostilizar os refugiados.

Essas autoridades só fazem coisas que não são do agrado do povo. Meteram os filhos desses estrangeiros nas escolas dos nossos. Os professores já andam esgotados, a fome aperta e ainda por cima têm que aturar os filhos desses cães. O que vale é que esses jovens professores são de gancho. Não permitem nem o mais pequeno desvio desses ranhosos. Há sempre um sopapo porque tossiu, mais outro porque se distraiu, uma expulsão por falta de comparência mesmo por motivo de doença. Assim, todas as crianças que foram metidas na escola, acabam por estar fora dela." (CHIZIANE,p. 81)

Catarina Koltai (2000) lembra-nos de que o desejo de eliminar o estrangeiro só ocorre porque ele é também um semelhante. Paulina Chiziane comprova essa ideia quando mostra o desejo que os de Mananga têm de exterminar os de Macuácua ao perceberem que eles possuem as mesmas necessidades que as suas: escola, alimentação, saúde, moradia. Embora todos sejam moçambicanos, a diferença se dá pela etnia. Não se pode esquecer, ainda, que se vive em um contexto de guerra civil, em que são bem maiores as privações e, consequentemente, a disputa pela sobrevivência.

Os de Mananga sentem-se irritados com a presença, os costumes e o modo de agir do povo de Macuácua.

Se vissem as choças onde dormem! Sem jeito. Sem forma. Sem estética. Apanham ramos de qualquer árvore para fazerem o abrigo. Depois metem a palha de qualquer maneira. Com tantas estacas a morrer nos campos, eles preferem viver assim. São inúteis. Preguiçosos. Uma raça sem dignidade. (CHIZIANE,p. 81) 
Devido à proximidade da guerra, à seca, à fome e, principalmente, ao brutal ataque protagonizado por Sianga, os moradores de Mananga sobreviventes da hecatombe resolvem partir em busca de um lugar distante e protegido, a aldeia do Monte. Ironicamente, os aldeões se reconhecem em situação muito semelhante à do povo que tanto desprezavam.

Os aldeões estão desorientados, mas os de Macuácua estão mais calmos e nem choram. Já foram graduados na academia de sofrimento [...] Dão a mão fraterna, solidária, aos novos estagiários da mesma academia, esquecendo o ostracismo e as hostilidades de que foram vitimas. (CHIZIANE,p. 95)

O arrependimento por terem tratado mal o povo vizinho só ocorre quando, já no Monte, os refugiados de Mananga são bem recepcionados e "sentem remorsos das atitudes passadas" (CHIZIANE,p. 139).

Quando se é colocado na condição de estrangeiro, na acepção político-cultural do termo, é mais fácil compreender o outro, porque é nesse momento que se dá a consciência de que, embora diferentes, somos semelhantes e feitos da mesma matéria humana.

Num contexto tão conturbado, outras duas personagens são representativas nessa narrativa de nação: Dambuza e Minosse. Eles se revelam como uma parte da aldeia não abraçada pelo sentimento de pertença.

Dambuza é um membro do grupo sem reconhecimento, uma vez que ele está junto à comunidade, mas não tem participação efetiva nela. Minosse ocupa, num primeiro momento, o lugar de subalternidade relegado à mulher nas sociedades patriarcais. Ela é excluída, mas é uma personagem ambivalente, pois, mesmo submissa, é ela a detentora do poder de constituir e manter a família. Na travessia em direção a Monte, a mulher persegue a vida. Na segunda parte da narrativa, no exílio, ela se mostra sábia, mestre de um futuro incerto. Minosse transita entre lugares/papéis diferentes. 


\section{Dambuza}

A psiquiatra Neusa Santos Souza define assim o estrangeiro:

O estrangeiro, diz o senso comum, é o outro. Outro que se afirma em muitos sentidos: outro país, outro lugar, outra língua, outro modo de estar na vida, de fruir, de gozar. O estrangeiro é o outro do familiar, o estranho; o outro do conhecido, o desconhecido; o outro do próximo, o distante, o que não faz parte, o que é de outra parte. (SOUZA, 1998, p.155)

Observa-se, na definição da estudiosa, que o termo estrangeiro associa-se não só ao legalmente identificado como natural de outro lugar, mas também ao modo de "estar na vida", ao comportamento que foge a uma regra estabelecida por um grupo social.

No segundo capítulo do livro Ventos do apocalipse, o narrador nos apresenta a personagem Dambuza²:

Ninguém entende este rapaz. É tímido, desconfiado, fugidio como uma gazela assustada, mas vemo-lo todos os dias nas savanas como um rei, solitário, altivo, tocando a flauta de cana. Quando passeia nos carreiros muitas vezes esconde-se nos arbustos para evitar o cumprimento de qualquer viandante. Parece mudo. Responde sempre com meias palavras e de cabeça baixa. Da sua boca nunca se ouviu injúria, um queixume de fome, de sede ou de qualquer outra coisa. Algumas vezes brinca ao lado dos rapazes da sua idade, mas nunca com eles. Nada o parece incomodar. No seu rosto não se lê esperança ou desespero. Umas vezes dá a impressão de ser feliz e noutras infeliz. Um dia parece ter oito anos e noutro dia parece ter oitenta. Ninguém lhe conhece a idade, parece homem, parece criança. Está sempre em todo o lado e em lado nenhum. [...] Até parece um javali roendo os ossos das nossas sepulturas, ninguém entende este rapaz. Dizem que ele se chama Dambuza, mas o povo chama-lhe Mufambi, aquele que caminha. Nasceu numa aldeia distante da nossa. É da nossa tribo mas não é do nosso clã. É um estrangeiro. É filho do irmão da tia Mafuni, e foi ela que o transportou para aqui. Dizem que foi abandonado pelo pai; que depois morreu a mãe. [...] Comia sozinho e escondido atrás da palhota, com medo de ser vaiado pelos primos que lhe macaqueavam o apetite quando mergulhava a mão inteira na bacia de madeira, e lambia o prato esvaziado. É um selvagem,

2 A citação é longa, mas necessária para a análise proposta. 
não tem a finura do nosso clã, é um estrangeiro. Mesmo nas brincadeiras, a discriminação era notória. No jogo da homa ele é que procurava as bolas de laranja macaco que saltavam o risco perdendo-se na mata. O mesmo acontecia no jogo de paulito. Nas escondidas cabia-lhe sempre o papel da procura, enquanto os outros gozavam a melhor parte do jogo. Dizendo a verdade, todo o mundo atormentava-o. Para quê tratá-lo bem se ele não é do nosso clã? $\mathbf{E}$ um estrangeiro e, se sente mal, que regresse à sua origem. (CHIZIANE, p. 25-26, grifos nossos.)

Retomando a definição de Neusa Souza, Dambuza é diferente, de outra parte. É interessante como o narrador inicia a apresentação do personagem, mostrando o modo como ele é visto pelas pessoas de Mananga. Ele não é compreendido porque não se faz compreensível: quase não fala, não se conhece a idade que tem. Percebe-se que Paulina Chiziane usa o termo estrangeiro na acepção de diferente, mas também daquele cujas origens remontam a outro lugar.

Dambuza é de outra parte, de outra aldeia, não pertence ao clã. A primeira justificativa para ser considerado um estrangeiro, portanto, é não ter ancestrais comuns aos demais da aldeia. A segunda justificativa é o fato de ser um selvagem, não comer com a civilidade dos demais. Já que não faz parte do clã, pode-se, pois, desrespeitar Dambuza. Ainda é dada ao estrangeiro a sugestão de sair do lugar do mal-estar e procurar o seu lugar, onde ele, certamente, vivenciará o sentimento de pertença: "É um estrangeiro e, se sente mal, que regresse à sua origem" (p. 26).

Apesar do reconhecimento de um elemento de identificação entre Dambuza e o povo de Mananga: "É da nossa tribo" (p. 25), nega-se a esse rapaz, por três vezes, a possibilidade de ser aceito. Ele é um estrangeiro e ponto final.

Segundo Julia Kristeva (1994), o estrangeiro recua-se, protegendo-se da indiferença, mas, ao encontrar algo ou alguém que o toque, o estado de indiferença dissipa-se. Dambuza deixa de parecer indiferente a partir do seu encontro com o amor, personificado em Wusheni, a única personagem que se aproxima do rapaz discriminado. De temperamento rebelde, Wusheni transgride as ordens de Sianga, seu pai, recusando o marido escolhido por ele e namorando Dambuza. Essa 
escolha possivelmente se dá pelo reconhecimento de que ele é diferente dos homens de Mananga, que subjugam as mulheres: "- Meu Dambuza, amo-te, sim. Esta linguagem de amor só é válida para nós dois. Na nossa tribo a palavra amo-te significa vacas. Vacas para o lobolo e nada mais" (CHIZIANE, p. 28).

O amor não desfaz as diferenças. Convidado pela namorada a participar das celebrações que o povo acreditava que poria fim à seca em Mananga, Dambuza se nega: "Essas coisas são para os deuses de Mananga. Eu aqui sou um refugiado, um estrangeiro ao vosso clã. Os meus defuntos repousam em terras distantes" (CHIZIANE, p. 56). Dambuza reproduz o discurso dos aldeões e reafirma, assim, a sua condição de estrangeiro. Indagado por Wusheni a respeito de sua crença em Deus, mais uma vez Dambuza mostra a sua alteridade: "Eu gostaria de acreditar na vida como todos os homens, mas como posso fazê-lo no meio de uma completa desproteção, tão abandonado e tão só?” (p. 57). Vitimizado, o estrangeiro mostra revolta, pede apoio da pessoa amada, concorda em ir à celebração, mas confirma sua descrença: "- Virei, sim, mas por ti. Continuo a não acreditar nessa história. Durante todos os anos da minha existência nunca ouvi dizer que um homem desviou o caminho do sol" (p. 57).

Grávida, Wusheni vai morar com Dambuza, sem o apoio da família. Na ocasião do massacre em Mananga, comandado por Sianga, ocorre o fratricídio. Com a intenção de matar Dambuza, Manuma, irmão de Wusheni, vai até o local onde o casal mora. Para salvar o seu amado, Wusheni mata o irmão e é morta por ele. Desesperado, Dambuza comete suicídio, "Preferiu partir em busca da Wusheni e do filho ainda por nascer" (CHIZIANE, p. 103). Depois de tanto tempo vivendo sob a hostilidade de todos, Dambuza recusa-se viver sem a companhia da única pessoa que o via além da sua condição de estrangeiro. A personagem Dambuza, portanto, como os de Macuácua, representa não só a estrangeiridade, no sentido de deslocamento do espaço natal, mas, sobretudo, uma maneira diferente de comportar-se em relação à comunidade em que vive. 


\section{Minosse}

$\mathrm{Na}$ narrativa de Paulina Chiziane, destaca-se uma personagem feminina ambivalente: Minosse. Última esposa do régulo, ela é a mais submissa e fiel ao marido, pois é a única que não o abandona nos tempos dificeis. Minosse anula-se diante de Sianga, não tendo voz nem para se defender de injustas acusações, mas mantém uma consciência que se expressa numa fala de desabafo:

Minosse monologa em voz alta. Em poucas palavras resume a sua trajectória de esposa de um velho tonto. Fala para si, para o ar, quem quiser escutar que escute. // —Yô, Minosse, filha da minha mãe. Dizem que marido velho é garantia de carinho, felicidade e enganaram-te sem dúvida alguma. [...] // Linguagem de ausência. É solidão dialogando com a consciência. (CHIZIANE, p. 21)

Essa "linguagem de ausência" vai acompanhar a personagem até a aldeia do Monte, para onde vai com outros refugiados depois da morte de Sianga e dos seus filhos.

No texto "O tabu da virgindade" (Freud, 1917), a palavra estrangeiro aparece também se referindo à mulher, que é a representação daquilo que é estrangeiro ou estranho. O feminino é postulado como diferença, alteridade, o outro sexo, outro modo de gozo: "a mulher é diferente do homem, eternamente incompreensivel e misteriosa, estranha" (FREUD, 1917, p. 184). O feminino é visto como excedente, desmesura. A mulher apresenta a "pequena diferença" e são as pequenas diferenças que originam os sentimentos de estrangeiridade e, consequentemente, a hostilidade no trato. Na narrativa de Chiziane, o lugar da mulher na sociedade tradicional é mostrado, por vezes, com uma visão crítica:

Os pombos constroem os ninhos nos ramos que lhes agradam. Os bichos das selvas escolhem o parceiro que lhes agrada, que amam (...) As vacas no curral não têm a mesma sorte (...) A estas, 
o macho é imposto, goste ou não goste, cumpre-se a vontade do dono. Com as mulheres é assim mesmo. (CHIZIANE, p. 58).

Entretanto, são as mulheres as responsáveis pelo mbelele, porque se acredita que elas têm o "poder" de, com o ritual, pedir chuva, que trará a fartura e a sobrevivência. Durante a travessia em direção à cidade do Monte não é dada voz às mulheres, mas são elas que cuidam para que a vida se mantenha no grupo dos refugiados.

Minosse, desde o início da narrativa de Ventos do apocalipse, encarna a figura do estrangeiro, da diferença. O lugar "oficial" da mulher na sociedade tradicional é o da subserviência ao homem e o do cuidado. Mas, como se vê no romance, este lugar tão tradicionalmente demarcado é posto em conflito pela guerra, pela fome e pela própria "fortaleza" da personagem.

A Minosse não é dada voz enquanto é feita a perigosa travessia dos refugiados até o suposto paraíso terrestre. Chegando ao Monte, os farrapos humanos primeiro se prostram, mas, com o passar dos dias, vão se refazendo, se reconstruindo moral e fisicamente. Minosse, no entanto, aliena-se, parece ausente, o olhar incessantemente voltado para o céu. "Os de Mananga navegam na nova vaga, mas Minosse permanece na margem da onda. Ninguém entende porquê." (CHIZIANE,p. 153). Essa permanência na margem é a permanência do lugar tradicionalmente dado à mulher, mas o olhar direcionado ao céu dá a Minosse a sensação de liberdade - "Ergue o rosto e olha para o céu numa expressão de libertação total.” (p. 154) - o que é dissolvido pelas lembranças do passado: "Deixa-se arrastar no desfile de recordação que, como sempre, convergem no mesmo ponto. Sianga jovem. Sianga velho. Sianga régulo, polígamo e próspero. Sianga frustrado, de rabo sempre colado ao chão a inventar rabugices." (CHIZIANE,p. 156) Voltando à realidade, Minosse reconhece-se como o outro do marido, que é a matriz, o princípio a quem ela é subordinada. É melhor, pois, continuar a olhar para o céu, alienando-se.

No entanto, a ambivalência feminina é perceptível em Minosse. Na aldeia do Monte vive uma criança rejeitada por ser neta de um feiticeiro 
de quem, acreditam os aldeões, o menino herdou os poderes mágicos que utilizará quando for adulto. Em meio aos seus devaneios, Minosse recorda-se de Dambuza e, imediatamente, relaciona-o ao menino abandonado no Monte. Resolve acolhê-lo: "- Vem, menino. Dar-te-ei pão e abrigo e tu dar-me-ás o conforto da tua companhia. És três vezes órfão, eu sei. Os teus pais morreram, os defuntos te abandonaram e o povo inteiro te renega. Quero ser a tua mãe e tua avó [...]" (CHIZIANE, p. 162). A partir desse momento, Minosse fica lúcida. A relação de afeto que a liga à criança é a cura da alienação dessa mulher, que reconhece a sua estrangeiridade na do menino e, como percebe o teórico Homi K. Bhabha (2001), ocorre, na relação, uma reunião de exilados. Ambos, a velha e a criança, reúnem-se na fronteira, na margem da sociedade. Minosse, agrupando-se a esse núcleo identitário, vê a possibilidade da reconstrução do grupo familiar. A família, que garante a sobrevivência de um povo, tem a possibilidade de se reestruturar por meio das ações de Minosse.

A esse novo grupo familiar juntam-se outras crianças marginalizadas. Minosse forma, no exílio, uma nova família: "Nunca antes imaginara encontrar no desterro a família sepultada nas areias de Mananga" (CHIZIANE, p. 171).

A euforia da nova família cede lugar a uma nova preocupação: Minosse "sentiu um túmulo forte no fundo do peito" (p. 187). O pensamento de que tudo é transitório antecipa o luto. Minosse pressente que está próximo o momento de sua morte (a grande estrangeira de todos nós) e se entristece por não ter tempo para ajudar Sara, a menina acolhida, a desvendar os segredos da vida. Para esta, então, viver a sua alteridade será mais dificil, pois não terá outra mulher para ensiná-1he tal ofício.

Nesse clima de angústias e tristezas, despede-se da narrativa Minosse, personagem representante, dentre outras coisas, da estrangeiridade culturalmente relegada à mulher.

\section{Conclusão}


Todo estrangeiro é um sobrevivente, uma vez que sobrevive à perda do espaço, da terra, da língua, enfim, sobrevive à perda do familiar. Sobrevive apesar das adversidades que representa e da hostilidade recebida. Discussões sobre a sobrevivência e sobre o estrangeiro, conceito atrelado à alteridade, à diferença, à exclusão, perpassam as narrativas de Chiziane.

Em Ventos do apocalipse, várias são as representações do estrangeiro, nas acepções política, cultural e social, que têm em comum a busca da redenção. As pessoas vindas de Macuácua vivem-na na fuga dos de Mananga para a aldeia do Monte. Dambuza tem sua redenção no amor de Wusheni e no suicídio. Já Minosse vive sua salvação na maternidade tardia, realizada com a nova família construída no exílio.

Sixpence, o herói dos refugiados; Emelinda, a delatora que promove o batismo de sangue em Monte; Danila, a enfermeira das forças humanitárias, são outras presenças estrangeiras na narrativa da africana Paulina Chiziane. Todos, em Ventos do apocalipse, estão, de alguma forma, marginalizados. Os diferentes, os pertencentes a outros clãs, as mulheres, as comunidades periféricas, todos estão às margens. A própria estrutura do texto de Paulina Chiziane apresenta-se à margem, pois evidencia um diálogo constante entre gêneros diferentes. No romance convivem contos orais, cantigas, provérbios, produzindo entrelaçamentos entre os diferentes gêneros textuais.

A narrativa de nação proposta pela autora constrói-se com discursos em conflito. A voz da tradição, que vê no elemento exógeno (estrangeiro) uma ameaça, convive com outras vozes marginais. Chiziane propõe, mesmo com um desfecho tão trágico, que é nas intermediações, no diálogo, que podem estar soluções geradoras de paz.

\section{Referências bibliográficas}

ARBEX JR, José. "A construção do estrangeiro pela mídia” In.: KOLTAI, Caterina [org] O Estrangeiro. São Paulo: Escuta / FAPESP, 1998. 
BHABHA, Homi K. "Disseminação: tempo, narrativa e as margens da nação moderna" In.: BUESCU, Helena; DUARTE, João Ferreira; GUSMÃO, Manuel. [org] Floresta encantada: novos caminhos da literatura comparada. Lisboa: Publicações Dom Quixote, 2001.

CHIZIANE, Paulina. Ventos do apocalipse. República de Moçambique: Edição da Autora, 1993.

FREUD, Sigmund (1917). "O tabu da virgindade" In: Edição Standard Brasileira das Obras Psicológicas Completas de Sigmund Freud, v. XI. Rio de Janeiro: Imago, 1970.

FREUD, Sigmund (1926). "Inibição, sintoma e angústia" In: Edição Standard Brasileira das Obras Psicológicas Completas de Sigmund Freud, v. XX. Rio de Janeiro: Imago, 1976.

FREUD, Sigmund (1929). "O mal-estar na civilização" In: Edição Standard Brasileira das Obras Psicológicas Completas de Sigmund Freud, v. XXI. Rio de Janeiro: Imago, 1974.

KOLTAI, Caterina. "Desamparo e a questão do estrangeiro" In:. Psychê: revista de Psicanálise, São Paulo, Ano IV, n. 6, p.95-103, nov. 2000. KRISTEVA, Julia. Estrangeiros para nós mesmos. Rio de janeiro: Rocco, 1994.

SOUZA, Neusa Santos. "O estrangeiro: nossa condição" In.: KOLTAI, Caterina [org] O Estrangeiro. São Paulo: Escuta / FAPESP, 1998. 